\title{
Performance Improvement of Distribution System by Using PROMETHEE - Multiple Attribute Decision Making Method
}

\author{
S. Kamble ${ }^{1}$ and U. Patil ${ }^{2}$ \\ 1 \\ Research Scholar, at Dr. B.A.T.U. Lonere-Raigad, India \\ ${ }^{2}$ Assistant Profressor, at Dr. B.A.T.U. Lonere-Raigad, India \\ \{sachinkamble80@rediffmail.com; patil_uv@yahoo.com \}
}

\begin{abstract}
Distribution system (DS) delivers electrical power to the end users and is the first interface of the utility with the consumers. Due to deregulation and competition amongst distributors, distribution utilities are under pressure to minimize the losses and to improve reliability to enhance the overall performance. Keeping in view of these aspects the distribution system is reconfigured for the purpose of loss minimization, balancing the load on the feeders, relieving overloads, and maintenance. Each configuration (switching combination) is considered as alternative for the decision makers (DM) with attributes like voltage profile, reliability etc. Multi-attribute decision-making (MADM) is the branch of decision making which deals with assessing the number of alternatives based on some conflicting attributes. In this paper, Preference Ranking Organization Method for Enrichment Evaluations (PROMETHEE) is proposed for finding the compromised best configuration from available alternatives. MADM methods weighted sum method (WSM), weighted product method (WPM), Analytical Hierarchy Process (AHP) and Technique for Order Preference by Similarity to Ideal Solution (TOPSIS) are applied to sample distribution system and results are compared with PROMETHEE.
\end{abstract}

Keywords: Distribution system reconfiguration, Loss minimization, Multi-attribute decision making, TOPSIS, PROMETHEE.

\section{Introduction}

Power system consists of three main components generation, transmission and distribution system. The distribution system consists of the distribution lines and substations. Distribution system losses are in the range of 5$13 \%$ and it is considered the weakest link in the power system. Poor management and insufficient investment has increased power demand with increase in losses in distribution system.

After many decades of negligence, distribution system is receiving better focus now-a-days. Utilities are under continuous pressure to improve reliability and supply quality-power to the consumers due to competitive environment. Therefore, utilities must have accurate information concerning system performance to reduce operating cost and meet consumers' expectations. An improved distribution infrastructure and innovative practices can reduce losses and improve system reliability.

Nowadays, the electricity demand is increasing day by day and hence it is very important to reduce power losses of existing distribution system. For the better performance of distribution system, network topology is required to change. System reconfiguration means rearranging the distribution lines which connect various buses (loads) in a power system. Network reconfiguration in distribution system is performed by opening sectionalizing (normally closed) and closing tie (normally open) switches of the network. These switching are performed in such a way that the radiality of the network is maintained and all the loads are energized without violating system constraints.

By changing status of switches, the power flow to loads will be changed and consequently affects the power loss, voltages, harmonic distortion level, as well as the system reliability. Hence, in normal operating condition performance of the distribution system can be improved by selecting the correct status of switches. In past, researchers have proposed various approaches to the network reconfiguration [9-16].

B. Iyer, S. Nalbalwar and R.Pawade (Eds.)

ICCASP/ICMMD-2016. Advances in Intelligent Systems Research.

Vol. 137, Pp. 493-498.

(C) 2017- The authors. Published by Atlantis Press

This is an open access article under the CC BY-NC license (http://creativecommons.org/licens)es/by-nc/4) 


\section{Multiple Criterion decision making (MCDM) methods}

Multiple criterion decision making (MCDM) methods are used for decision making in multiple criteria problems. These methods are further classified as Multiple objective decision making (MODM) methods and multiple attribute decision making (MADM) methods.

MODM methods are used when objectives are many, and one has to decide the best while satisfying the constraints and preference priorities. MADM is an approach used to solve problems with limited number of predetermined alternatives. For complex decisions in terms of the consideration of multiple factors, researchers have focused on Multi Attribute Decision Making (MADM) techniques.

In MADM, several alternatives (options) according to some attributes (criteria) are ranked. Ranking is made among decision alternatives described using some criteria (factors) by decision-makers' knowledge and experience.

Each decision table or decision matrix in MADM methods have alternatives, attributes, weight or relative importance of each attribute, and measures of performance of alternatives. The decision matrix is shown in Table 1. The decision table shows alternatives, $\mathrm{Ai}$ (for $\mathrm{i}=1,2, \ldots ., \mathrm{N}$ ), attributes, $\mathrm{Bj}$ (for $\mathrm{j}=1,2, \ldots . ., \mathrm{M}$ ), weights of attributes, wj (for $\mathrm{j}=1,2, \ldots ., \mathrm{M}$ ) and the measures of performance of alternatives, mij (for $\mathrm{i}=1,2, \ldots . ., \mathrm{N}$; $\mathrm{j}=1,2, \ldots ., \mathrm{M})[2]$.

The job of the decision maker is to select the best alternative from the given alternatives in the form of decision table or matrix. All the elements in the decision table or matrix must be normalized to bring all the attributes on the common platform.

Table 1: Decision table or Matrix in MADM methods [2]

\begin{tabular}{|c|c|c|c|c|c|c|}
\hline \multirow[b]{2}{*}{ Alternatives } & \multicolumn{2}{|c|}{ Attributes } & \multirow[b]{2}{*}{$\begin{array}{l}\text { B3 } \\
\text { (w3) }\end{array}$} & \multirow[b]{2}{*}{$\begin{array}{l}- \\
(-)\end{array}$} & \multirow[b]{2}{*}{$\begin{array}{l}- \\
(-)\end{array}$} & \multirow[b]{2}{*}{$\begin{array}{l}\text { BM } \\
(w M)\end{array}$} \\
\hline & $\begin{array}{l}\text { B1 } \\
\text { (w1) }\end{array}$ & $\begin{array}{c}\text { B2 } \\
\text { (w2) }\end{array}$ & & & & \\
\hline A1 & $\mathrm{m} 11$ & $\mathrm{~m} 12$ & $\mathrm{~m} 13$ & - & - & $\mathrm{m} 1 \mathrm{M}$ \\
\hline $\mathrm{A} 2$ & $\mathrm{~m} 21$ & $\mathrm{~m} 22$ & $\mathrm{~m} 23$ & - & - & $\mathrm{m} 2 \mathrm{M}$ \\
\hline A3 & $\mathrm{m} 31$ & m32 & m33 & - & - & $\mathrm{m} 3 \mathrm{M}$ \\
\hline- & - & - & - & - & - & - \\
\hline- & - & - & - & - & - & - \\
\hline AN & $\mathrm{mN} 1$ & $\mathrm{mN} 2$ & $\mathrm{mN} 3$ & - & - & $\mathrm{mNM}$ \\
\hline
\end{tabular}

The most commonly used multi criteria decision making techniques are-

- Weighted Sum Method (WSM)

- Weighted Product Method (WPM)

- AHP (Analytic Hierarchy Process)

- TOPSIS (For the Technique for Order Preference by Similarity to Ideal Solution)

- $\quad$ ELECTRE (For Elimination and Choice Translating Reality)

- $\quad$ PROMETHEE (Preference Ranking Organization Method for Enrichment Evaluations)

\section{Preference Ranking Organization Method for Enrichment Evaluations (PROMETHEE)}

The Preference Ranking Organization Method for Enrichment Evaluations (PROMETHEE) was developed by Brans et al. (1984) and falls in the category of outranking methods. In PROMETHEE, pair wise comparison of alternatives is prepared for each single criterion to determine partial binary relations denoting the strength of preference of one alternative over the others. In the evaluation table, the alternatives are evaluated with diverse criteria. To solve the problem by using PROMETHEE some additional information is required like relative importance or the weights of the criteria, and the decision maker's preference function.

The procedure of decision making for solving distribution system problem using PROMETHEE method is as follows: 
Step1: Identify and short-list the alternatives on the basis of the identified criteria.

Step2: Prepare a decision table or decision matrix.

Step3: Get the information on the decision maker preference function. The preference function (Pi) translates the difference between the evaluations obtained by two alternatives (a1 and a2) in terms of a particular attribute, into range from 0 to 1 . Let $P i, a l a 2$ be the preference function associated to the attribute $b j$.

$$
\begin{aligned}
P i, a 1 a 2 & =G i[c i(a 1)-c i(a 2)] \\
0 & \leq P i, a 1 a 2 \leq 1
\end{aligned}
$$

If the decision maker specifies a preference function $P i$ and weight $w i$ for each attribute ' $b j$ ' of the problem, then the multiple attribute preference index Gala2 can be calculated as the weighted average of the preference functions $\mathrm{Pj}$.

$$
\prod a 1 a 2=\sum_{i=1}^{M} w i P i, a 1 a 2
$$

Step 4: Calculate the leaving flow $\varphi^{+}(a)$.

$$
\varphi^{+}(a)=\sum_{x \in A} \prod x a
$$

Step 5: Calculate the entering flow $\varphi^{-}(\mathrm{a})$.

$$
\varphi^{-}(a)=\sum_{x \in A} \prod a x
$$

Step 6: Calculate the net flow $\varphi(a)$.

$$
\varphi(a)=\varphi^{+}(a)-\varphi^{-}(a)
$$

Step 7: Decide the ranking based on the scores of net flow.

The PROMETHEE method provides a ranking of the alternatives from the best to the worst one using the net flows.

\section{Implementation and Results}

The example of $12.66 \mathrm{kV}, 33$-node system is taken into consideration as a case study. This has many possible radial configurations, but only non-dominated solutions [1] are taken as shown in Table 2 . The weights of the attributes considered in [1] are 0.3 for the active power losses, 0.35 for system average interruption frequency index (SAIFI) (failures/year) and 0.35 for average energy not supplied (AENS) (kWh/customer/year).

The available alternatives for DM are 14, and attributes considered are 3, active power losses, SAIFI and AENS, all the attributes are required to be minimized for the benefit of the distribution system.

Table 2: Example from Reference [1]

\begin{tabular}{cccc}
\hline Solution & Losses & SAIFI & AENS \\
\hline 1 & $\mathbf{1 3 9 . 5 5 1 3}$ & 1.1048 & 0.4422 \\
2 & 139.9780 & 1.0327 & 0.4118 \\
3 & 141.9160 & 1.0173 & 0.4056 \\
4 & 142.4292 & 1.0162 & 0.4054 \\
5 & 146.2891 & 1.0042 & 0.3998 \\
6 & 146.5133 & 1.0031 & 0.3995 \\
7 & 146.6658 & 1.0021 & 0.3999 \\
8 & 148.6078 & 0.9982 & 0.3991 \\
9 & 150.2031 & 1.0003 & 0.3984 \\
10 & 150.2483 & 0.9991 & 0.3982 \\
11 & 150.9774 & 0.9910 & 0.3952 \\
12 & 152.5900 & 0.9871 & 0.3943 \\
13 & 156.0999 & 0.9847 & 0.3936 \\
14 & 161.5802 & $\mathbf{0 . 9 8 4 1}$ & $\mathbf{0 . 3 9 3 5}$ \\
\hline
\end{tabular}

Table 3: Normalized values

\begin{tabular}{cccc}
\hline Solution & Losses & SAIFI & AENS \\
\hline 1 & 1.0000 & 0.8907 & 0.8899 \\
2 & 0.9970 & 0.9529 & 0.9556 \\
3 & 0.9833 & 0.9674 & 0.9702 \\
4 & 0.9798 & 0.9684 & 0.9706 \\
5 & 0.9539 & 0.9800 & 0.9842 \\
6 & 0.9525 & 0.9811 & 0.9850 \\
7 & 0.9515 & 0.9820 & 0.9840 \\
8 & 0.9391 & 0.9859 & 0.9860 \\
9 & 0.9291 & 0.9838 & 0.9877 \\
10 & 0.9288 & 0.9850 & 0.9882 \\
11 & 0.9243 & 0.9930 & 0.9957 \\
12 & 0.9146 & 0.9970 & 0.9980 \\
13 & 0.8940 & 0.9994 & 0.9997 \\
14 & 0.8637 & 1.0000 & 1.0000 \\
\hline
\end{tabular}




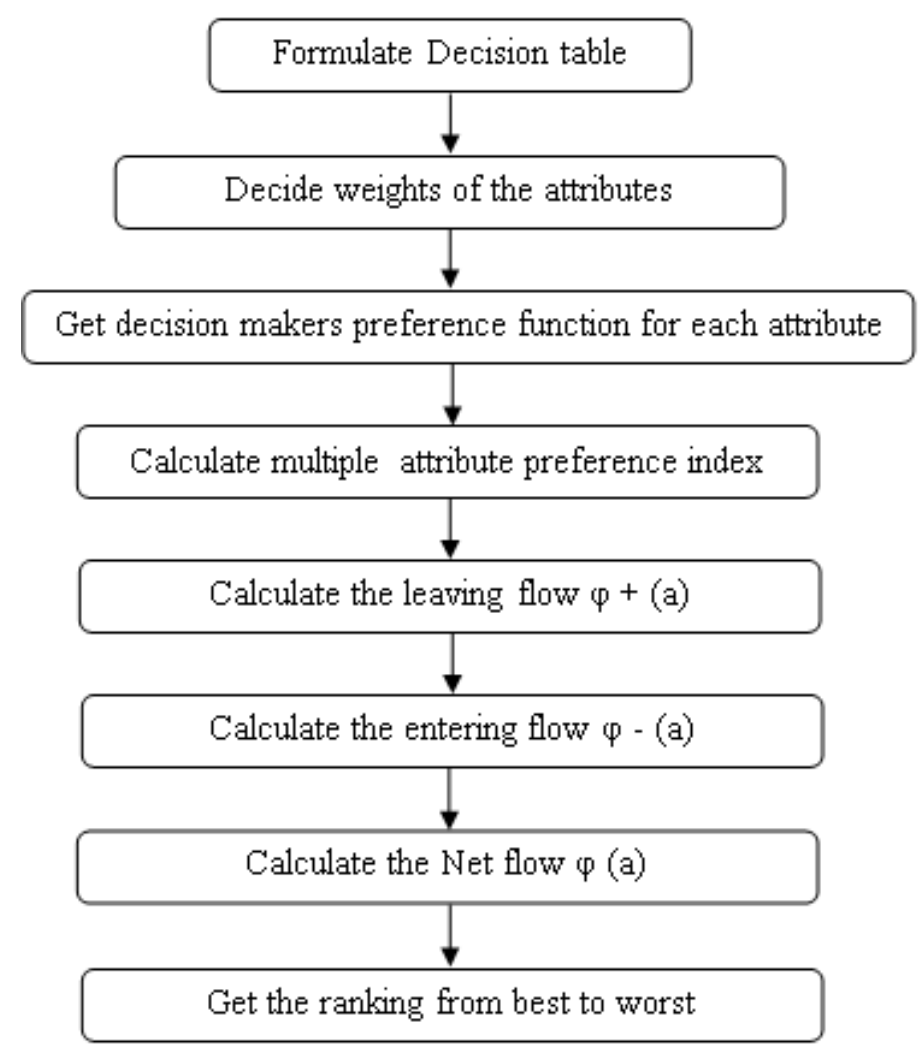

Fig. 1: Flow chart for PROMETHEE method

Table 4: Result Table of PROMETHEE method

\begin{tabular}{llllllllllllllllll}
\hline & A1 & A2 & A3 & A4 & A5 & A6 & A7 & A8 & A9 & A10 & A11 & A12 & A13 & A14 & $\begin{array}{c}\text { Net } \\
\text { Dominance }\end{array}$ & Ranking \\
\hline A1 & - & 0.3 & 0.3 & 0.3 & 0.3 & 0.3 & 0.3 & 0.3 & 0.3 & 0.3 & 0.3 & 0.3 & 0.3 & 0.3 & -7.90 & 14 \\
A2 & 0.7 & - & 0.3 & 0.3 & 0.3 & 0.3 & 0.3 & 0.3 & 0.3 & 0.3 & 0.3 & 0.3 & 0.3 & 0.3 & -7.10 & 13 \\
A3 & 0.7 & 0.7 & - & 0.3 & 0.3 & 0.3 & 0.3 & 0.3 & 0.3 & 0.3 & 0.3 & 0.3 & 0.3 & 0.3 & -6.30 & 12 \\
A4 & 0.7 & 0.7 & 0.7 & - & 0.3 & 0.3 & 0.3 & 0.3 & 0.3 & 0.3 & 0.3 & 0.3 & 0.3 & 0.3 & -5.50 & 11 \\
A5 & 0.7 & 0.7 & 0.7 & 0.7 & - & 0.3 & 0.65 & 0.3 & 0.3 & 0.3 & 0.3 & 0.3 & 0.3 & 0.3 & -4.00 & 10 \\
A6 & 1 & 1 & 1 & 1 & 1 & - & 1.65 & 1.3 & 1.3 & 1.3 & 1.3 & 1.3 & 1.3 & 1.3 & 6.60 & 1 \\
A7 & 1 & 1 & 1 & 1 & 0.65 & 0.65 & - & 1.3 & 1.3 & 1.3 & 1.3 & 1.3 & 1.3 & 1.3 & 3.90 & 3 \\
A8 & 1 & 1 & 1 & 1 & 1 & 1 & 1 & - & 1.65 & 1.65 & 1.3 & 1.3 & 1.3 & 1.3 & 6.10 & 2 \\
A9 & 1 & 1 & 1 & 1 & 1 & 1 & 1 & 0.65 & - & 1.3 & 1.3 & 1.3 & 1.3 & 1.3 & 3.40 & 4 \\
A10 & 1 & 1 & 1 & 1 & 1 & 1 & 1 & 0.65 & 1 & - & 1.3 & 1.3 & 1.3 & 1.3 & 2.80 & 6 \\
A11 & 1 & 1 & 1 & 1 & 1 & 1 & 1 & 1 & 1 & 1 & - & 1.3 & 1.3 & 1.3 & 2.90 & 5 \\
A12 & 1 & 1 & 1 & 1 & 1 & 1 & 1 & 1 & 1 & 1 & 1 & - & 1.3 & 1.3 & 2.30 & 7 \\
A13 & 1 & 1 & 1 & 1 & 1 & 1 & 1 & 1 & 1 & 1 & 1 & 1 & - & 1.3 & 1.70 & 8 \\
A14 & 1 & 1 & 1 & 1 & 1 & 1 & 1 & 1 & 1 & 1 & 1 & 1 & 1 & - & 1.10 & 9 \\
\hline
\end{tabular}


Table 5: Comparison of MADM methods with ranking obtained

\begin{tabular}{cccccc}
\hline Solution & WSM & WPM & AHP & $\begin{array}{c}\text { TOPSIS } \\
{[\mathbf{1}]}\end{array}$ & PROMETHEE \\
\hline 1 & 14 & 14 & 14 & 14 & 14 \\
2 & 13 & 11 & 12 & 10 & 13 \\
3 & 5 & 4 & 5 & 2 & 12 \\
4 & 6 & 6 & 6 & 4 & 11 \\
5 & 2 & 2 & 2 & $\mathbf{1}$ & 10 \\
6 & $\mathbf{1}$ & $\mathbf{1}$ & $\mathbf{1}$ & 3 & $\mathbf{1}$ \\
7 & 3 & 3 & 3 & 5 & 3 \\
8 & 8 & 8 & 10 & 6 & 2 \\
9 & 10 & 10 & 9 & 9 & 4 \\
10 & 9 & 9 & 4 & 8 & 6 \\
11 & 4 & 5 & 7 & 7 & 7 \\
12 & 6 & 7 & 11 & 11 & 8 \\
13 & 11 & 12 & 13 & 12 & 9 \\
14 & 13 & 13 & & 13 & \\
\hline
\end{tabular}

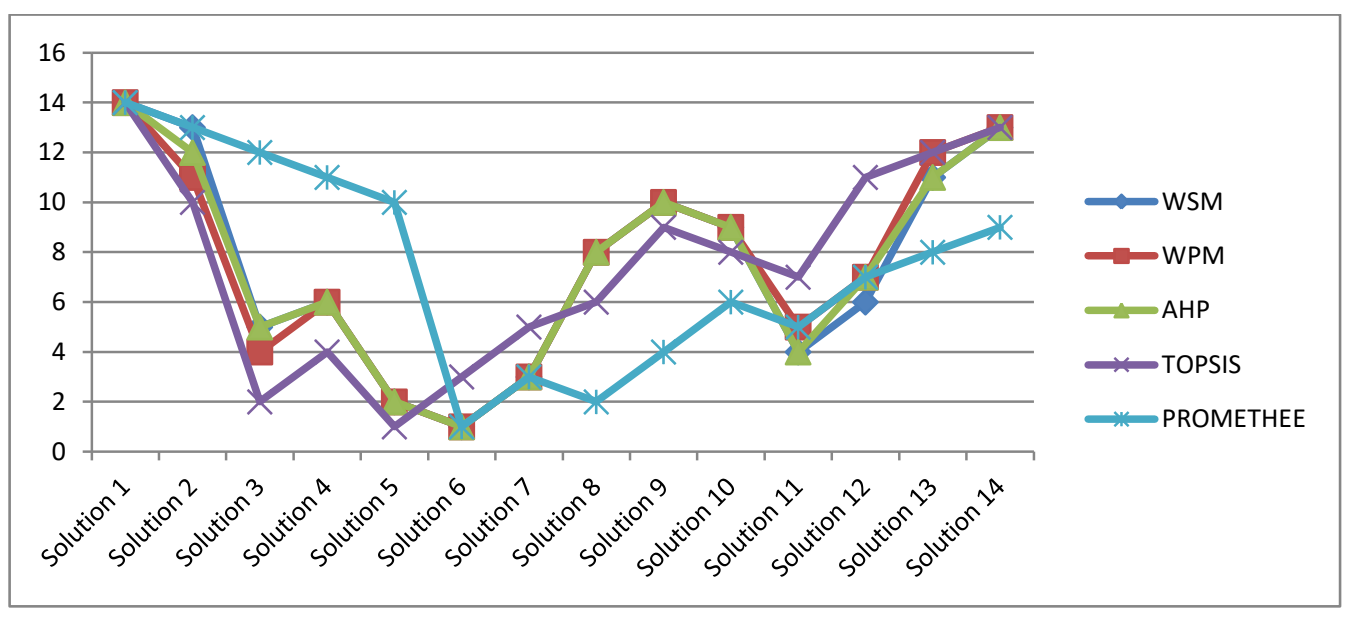

Fig. 2: Graphical representation of comparison of various MADM methods for example [1]

\section{Conclusion}

In this paper, MADM technique PROMETHEE is discussed in detail and WSM, WPM, AHP, TOPSIS, and PROMETHEE are implemented for the sample distribution system for decision making. The attributes considered are the minimization of the active power losses and the minimization of reliability indices (SAIFI, AENS). Weights considered are 0.3 for losses and 0.35 for SAIFI and 0.35 for AENS for all the methods.

The purpose of this paper is to find the optimal configuration by comparing different switching combinations with given attributes i.e. losses, SAIFI and AENS.

The results obtained by all the MADM methods are compared and solution number 6 has obtained rank 1 in WSM, WPM, AHP and PROMETHEE. The PROMETHEE method takes into account values of the criteria and their relative importance together. This results in better evaluation of the alternatives as compared to other methods and proves to be a good method for performance improvement of distribution system and its reconfiguration. 


\section{References}

[1] Nikolaos G. Paterakis, Andrea Mazza, Sergio F. Santos, Ozan Erdinç, Gianfranco Chicco, Anastasios Bakirtzis, and João P. S. Catalão, "Multi-Objective Reconfiguration of Radial Distribution Systems using Reliability Indices," IEEE Trans. On Power Systems, vol. 31, pp. 1048-1062, March 2016.

[2] R.Venkata Rao, Decision Making in the Manufacturing Environment, pp. 27-41. Springer-Verlag London Limited, 2007.

[3] R. Venkata Rao, B. K. Patel, "Decision making in the manufacturing environment using an improved PROMETHEE method" International Journal of Production Research, pp. 1-18, 2009, iFirst.

[4] E. Triantaphyllou, B. Shu, S. Nieto Sanchez, and T. Ray, "Multi-Criteria Decision Making: An Operations Research Approach" Encyclopedia of Electrical andElectronics Engineering, (J.G. Webster, Ed.), John Wiley \& Sons, New York, NY, Vol. 15, pp. 175- 186, (1998).

[5] P. Espie, G.W. Ault, G.M. Burt and J.R. McDonald, Multiple criteria decision making techniques applied to electricity distribution system planning, IEE Proceedings-Generation, Transmission and Distribution, 150(5)(2003) 527-535.

[6] Tiefeng ZHANG, Guangquan ZHANG, Jun MA, Jie LU, "Power Distribution System Planning Evaluation by a Fuzzy Multi-Criteria Group Decision Support System", International Journal of Computational Intelligence Systems, Vol.3, No. 4 (October, 2010), 474-485.

[7] S. Wong, K. Bhattacharya and J.D. Fuller, Electric power distribution system design and planning in a deregulated environment, IET- Generation, Transmission \& Distribution, 3(12) (2009) 1061-1078.

[8] IEEE Guide for Electric Power Distribution Reliability Indices, IEEE Std. 1366-2003, May 2004.

[9] D. Shirmohammadi and H. W. Hong, "Reconfiguration of electric distribution networks for resistive line losses reduction," IEEE Trans. Power Syst., vol. 4, no. 2, pp. 1492-1498, Apr. 1989.

[10] R. Srinivasa Rao, S. V. L. Narasimham, M. Ramalinga Raju, and A.Srinivasa Rao, "Optimal network reconfiguration of large-scale distribution system using harmony search algorithm," IEEE Trans. Power Syst., vol. 26, no. 3, pp. 1080-1088, Aug. 2011.

[11] M. E. Baran and F. F. Wu, "Network reconfiguration in distribution systems for loss reduction and load balancing," IEEE Trans. Power Del., vol. 4, no. 2, pp. 1492-1498, Apr. 1989.

[12] B. Amanulla, S. Chakrabarti, and S. N. Singh, "Reconfiguration of power distribution systems considering reliability and power loss," IEEE Trans. Power Del., vol. 27, no. 2, pp. 918-926, Apr. 2012.

[13] A. Kavousi-Fard and T. Niknam, "Optimal distribution feeder reconfiguration for reliability improvement considering uncertainty," IEEE Trans. Power Del., vol. 29, no. 3, pp. 1344-1353, Jun. 2014.

[14] Merlin and H. Back, "Search for a minimal-loss operating spanning tree configuration in urban power distribution systems," in Proc. 5th Power Syst. Comp. Conf., $\quad$ Cambridge, U.K., Sep. 1-5, 1975.

[15] S. K. Goswami and S. K. Basu, "A new algorithm for the reconfiguration of distribution feeders for loss minimization,” IEEE Trans. Power Del., vol. 7, no. 3, pp. 1484-1491, Jul. 1992.

[16] T. E. McDermott, I. Drezga, and R. P. Broadwater, "A heuristic nonlinear constructive method for distribution system reconfiguration," IEEE Trans. Power Syst., vol. 14, no. 2, pp. 478-483, May 1999. 